\title{
Volleyball Injuries: Brazilian Men's National Squad Sports Medicine Experience
}

\author{
Ney Coutinho Pecegueiro do Amaral ${ }^{1,2}$, Marco Martins Lages $^{1,2^{*}}$, Felipe Malzac Franco ${ }^{1,2}$, Felipe Serrão \\ Mendes de Souza ${ }^{1,2}$, Matheus Cardoso dos Santos ${ }^{2}$, Aridone Borgonovo ${ }^{2}$ and Vinícius Soares Santos ${ }^{2}$ \\ ${ }^{1}$ Serviço de Ortopedia e Traumatologia Prof. Nova Monteiro, Hospital Municipal Miguel Couto, Rio de Janeiro, Brazil \\ ${ }^{2}$ Confederação Brasileira de Voleibol, Saquarema, Brazil
}

\begin{abstract}
Our purpose is a descriptive epidemiology study of the most common injuries in high performance volleyball practice. All players were evaluated by our multidisciplinary staff of the Medical Department of Brazilian Men's National Team, at Volleyball Development Center, at Saquarema, Rio de Janeiro, Brazil. Important injuries, which lead to interruption of training or competitions, were included.
\end{abstract}

Keywords

Volleyball Injuries

\section{Introduction}

Volleyball is one the most popular sports in the world, being considered number two top sport in Brazil, after soccer [1]. Since volleyball is not full contact sports between opponents, theoretically, trauma injuries would have a lower incidence than other sports. However, competitive level has a higher demand of full body acceleration and immediate slowdown, eventually leading to injuries as regular as three injuries for every thousand hours played.

Some specific segments are usually overloaded, as knee at jumping and landing, and shoulder, at spikes and serves. A professional athlete, for example, can execute spike gesture for about forty thousand times a year [2]. Besides those overuse injuries, other segments are more vulnerable to trauma incidents, as the hand, at blocking and reception, and ankle, when landing [2].

Most studies search injuries origin, dividing in traumatic acute and chronical overuse severities [3]. Thereby, it is possible to relate incidence and prevalence to number of hours of practice [3]. During a competition period, the number of traumatic injuries might double, when compared to a training period [4].

Our study purpose is to identify which injuries are more prevalent in volleyball practice, and which body segments might be at risk in this sport.

\section{Material and Methods}

Athletes were submitted to clinical evaluation through our medical questionnaire, based at FIVB's M-10 question- naire [5] (Appendix 1), adapted by our staff. During training and competitions period with Brazil's National team, they were daily monitored by our multidisciplinary staff. All medical care performed that led to the absence of training for at least one day during season was included. Data included kind of injury, segment affected, age and time in which an athlete stood away without training at injury list, between May 2016 and October 2019.

\section{Results}

During our four years period of study, 104 athletes were evaluated, which involved preparation and competition, such as South American tournaments, 2017 and 2019 World Cup of four different age groups (U19, U21, U23 and professional adult), Nations League, and also included the 2016 Olympic Games, besides friendly matches and minor tournaments. Twenty-eight athletes did not suffer any kind of major injury during this period (26.92\%). The sum of injuries percentages gets higher than $100 \%$ participants, since some athletes had

*Corresponding author: Marco Martins Lages, Serviço de Ortopedia e Traumatologia Prof. Nova Monteiro, Hospital Municipal Miguel Couto, Rio de Janeiro; Confederação Brasileira de Voleibol, Saquarema, Brazil

Accepted: March 16, 2020

Published online: March 18, 2020

Citation: Amaral NCP, Lages MM, Franco FM, et al. (2020) Volleyball Injuries: Brazilian Men's National Squad Sports Medicine Experience. Arch Sports Med 4(1):178-183 
Citation: Amaral NCP, Lages MM, Franco FM, et al. (2020) Volleyball Injuries: Brazilian Men's National Squad Sports Medicine Experience. Arch Sports Med 4(1):178-183

more than one injury along those four years.

Most injuries were from overuse training, 66.93\%. Trauma injuries, which are more difficult to prevent, happened at $33.06 \%$ of cases. Ankle and fingers are more vulnerable to a traumatic event, while shoulder and knee are more likely to overuse harm. An overuse injury can be defined by any type of muscle or joint injury, such as tendinitis or a stress fracture, that's caused by repetitive trauma, from gradual or sudden onset. Traumatic injuries are represented by acute direct trauma from contact to another player (which can be from the same team or the opposite team), a moving object (such as ball), a stagnant object (such as post, bench or sponsors boards), or non-contact trauma [5].

Knee was the most common segment affected, followed by ankle, with $21.77 \%$ and $18.54 \%$ of injuries, numbers similar to world literature (27 and 23 injuries). Pelvis, shoulder, hand and spine complete the regular stats, also with similar incidence to literature, and can be considered vulnerable segments to be more common of injury at volleyball [2-4,6,7].

Some specific conditions deserve notice. Tendinopathy involving knee's extensor mechanism affected 24 athletes (23.07\%). Six athletes had bilateral symptoms, while one athlete that had not only quadricipital and patellar tendon symptoms, but also Osgood-Schlatter sequelae (there were 31 trigger points of pain in all 24 athletes). Most athletes had symptoms at proximal insertion of the patellar tendon ( 21 trigger points, or $67.7 \%$ ), with 8 athletes with quadricipital symptoms (25.8\%) and only two cases of Osgood-Schlatter sequelae (6.4\%), numbers similar to world literature $[7,8]$.

Most ankle injuries are related to traumatic events, as sprains, affecting specially the lateral ligament complex (86.95\% of ankle injuries). There were only three cases of Achilles tendinopathy.

Pelvic injuries were restricted almost to core muscle injuries due to overuse, affecting rectum femoris (one case, $6.6 \%$ ), hamstrings (4 cases, $26.6 \%$ ), adductors (also 4 cases), and rectum abdominis (5 cases, $33.3 \%$ ). There was only one case of trauma in that segment, with local muscular bruise.

Despite not being the most common place for injuries, shoulder exhibits some typical "over the head" particularities. Mostly, there are rotator cuff and superior labrum anteroposterior injuries (SLAP), typical from the throwing shoulder (76.9\%). In four cases, there was a neuropathy of suprascapular nerve, with infraspinatus atrophy associated to those injuries ( $30.7 \%$ of all shoulder injuries). There were three traumatic events, to the acromion-clavicular joint (23\%). There were 13 injuries during our study, which represents $10.48 \%$ of all injuries.

Hand is also vulnerable to finger fractures and sprains, specially at blocking and reception, with centers and liberos being at risk. There were twelve cases ( $9.67 \%$ of all injuries), mostly fractures and sprains (9 cases, $75 \%$ of hand injuries). There were three cases of sprained thumb, two cases of fracture of fifth finger, and only one case of sprain at second, third and fourth fingers. There was also a stress fracture of the third metacarpal bone.

Another hand injury deserves a special attention. Hypothenar hammer syndrome was observed in two athletes (16.6\% of all hand injuries), and lead to a minimum two-month period of rest before returning to training. This condition is a thrombotic overuse injury that affects ulnar artery at Guyon's tunnel, due to repeated trauma. It affects elite volleyball players, specially spikers [1]. In both of our cases, it appeared in a player of opposite hitter position.

Also caused by repeated local trauma, there were 8 cases of stress reaction at lower limb, with 6 cases of Medial Tibial Stress Syndrome and two cases of stress fracture of metatarsals (one at the fourth toe and one of the fifth metatarsal). Around $7.7 \%$ of all athletes suffer with some kind of bone stress injury during our study period.

There were 11 cases of athletes with spine symptoms, most of them with lumbar pain due to muscular overload. There were three cases of herniated lumbar disc, one of them leading to surgery. There was also one case o stress fracture of $L 5$.

There were also four traumatic injuries to face $(3.22 \%$ of all injuries), being two eyelid bruises from trauma against ball, one nose fracture and one zygomatic arch fracture, both from trauma to player from same team.

Elbow was an unusual site for injury, with only three reports (2.42\% of all injuries), with two cases of medial epicondylitis, and one case of pronator syndrome, all due to load overuse during spike.

Injury incidence according to each segment is displayed at Infographic 1.

\section{Discussion}

Ankle injuries prevalence was observed at Norwegian players [4], reminding a recurrence rate up to $80 \%$ of sprain injuries. In fact, there were recorded $44 \%$ of injuries affecting this joint during American National Collegiate Athletic Association women's tournament, highlighting the importance of well protection of this area while training [6].

Most ankles injuries are traumatic, being sprain with compromise of lateral ligament complex being the most common mechanism. Previous injuries increase chance of a new injury. Origin of trauma might vary, may be from contact against another athlete or ball during landing, or without contact at all, specially in athletes with previous injury. Ankle protection with braces and proprioception training are essential in preventing work for new injuries $[9,10]$.

Despite the high incidence of extensor mechanism tendinopathy, which may be up to $50 \%$ of volleyball athletes, this injury does not mean necessarily a constant withdrawal from training [11]. At Brazilian national team, 23.7\% of all players were injury listed for this condition. Most athletes keep training and playing, even with pain, increasing risk of partial and total ruptures - there was one case of partial rupture of quadricipital tendon, which had to be treated surgically, a lower 


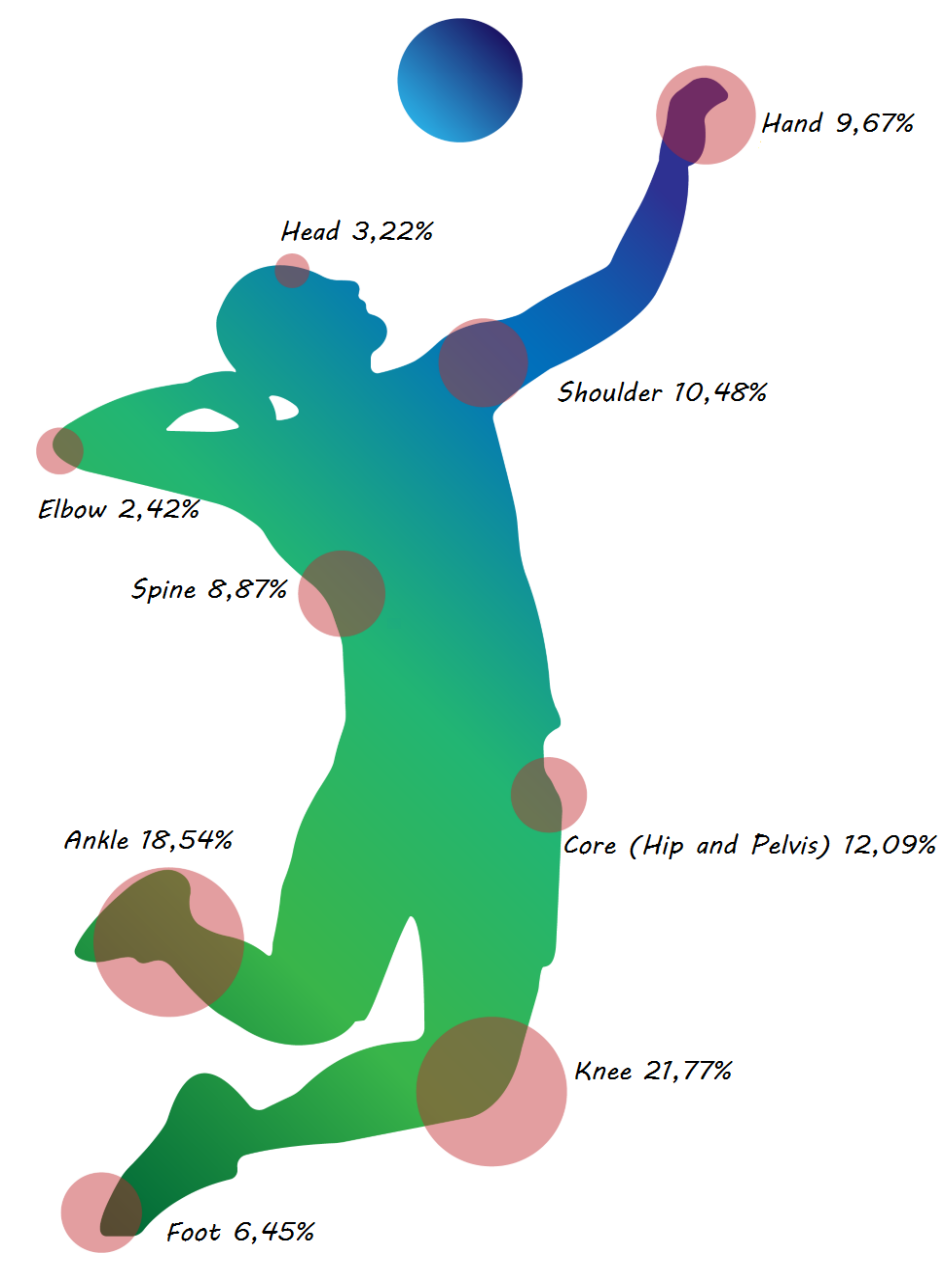

Infographic 1: Volleyball injuries by segment.

incidence that found in literature [7].

Younger athletes usually suffer more from Osgood-Schlatter disease sequel pain. Many players present the deformity, but not necessarily have the symptoms. Severity of those symptoms might be related directly from number of jumps in trainings and competitions. Also, a hard surface in courts, that sometimes can be showed during some small tournaments, increases greatly patellar and quadricipital tendons pain [12].

Since pain location might vary, there is a recommendation that the terms "patellar tendinopathy" and "jumper's knee" are insufficient and imprecise, and should be abandoned as the expression "knee's extensor mechanism" seems more suitable [8].

At last to this subject, corrections in landing techniques, with a better distribution of force vectors at both legs, combined with specific squat and proprioception training, improves effectiveness of knee extensor mechanism, and decreases incidence of tendinopathy, as well as patellar chondropathy $[13,14]$.

Shoulder is another joint that is subjected to high forces in this sport, being at risk for both acute and overuse injuries. Rotator cuff tears, internal impingement, suprascapular neuropathy, superior labral anteroposterior (SLAP) injuries are commonly described in literature, as well as scapular mal- position, inferior border prominence, coracoid pain and malposition, and dyskinesis of scapular movement (SICK scapula) $[8,15,16]$. There were five cases of SICK scapula during our experiment, but none of those cases lead to absence from training due to injury. They all manage to keep training with controlled pain.

Those injuries are more likely to be found at attackers, which overload this joint, exhibiting anatomic variations typical of throwing shoulder, with dorsal muscles and the posterior and inferior part of the shoulder capsule shortened, and loosening of anterior ligaments, with glenohumeral internal rotation deficit and increase of external rotation [17].

Since this sport requires a sudden and complex over-thehead movement, which involves external rotation, abduction am flexion, followed by sudden internal rotation, adduction and extension, all associated to rotational chest movements, physical and kinematic adaptations occur, similar to throwing shoulder sports, like baseball [18]. It is fundamental to understand all throwing phases - wind-up, cocking, deceleration and follow-through - in order to comprehend those injuries. Theses phases at volleyball spike are described in Figure 1.

Suprascapular neuropathy can regularly be found in elite players. This nerve is entrapped at scapular notch due to a hypertrophic transverse scapular ligament, which is associ- 

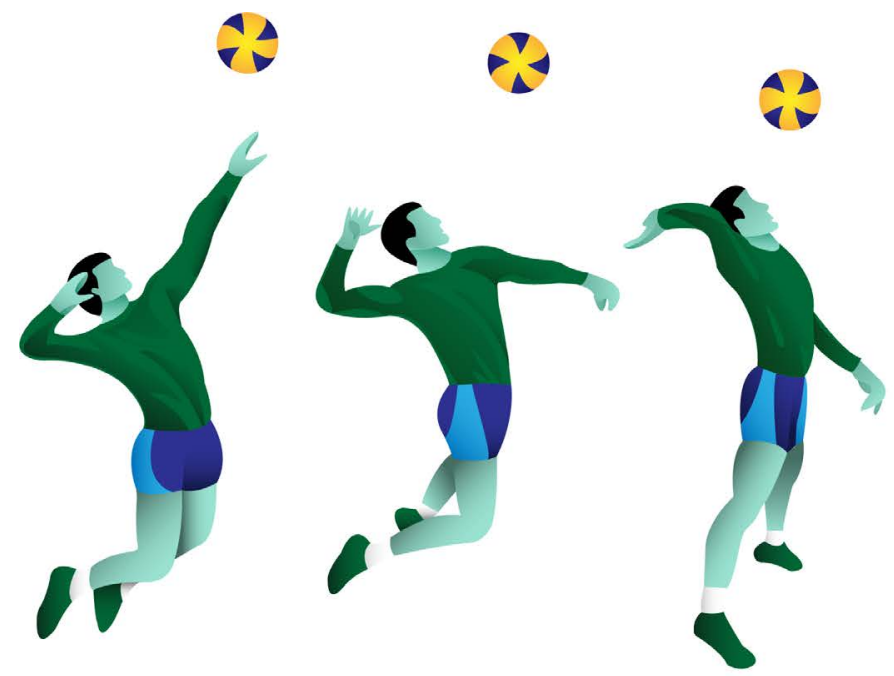

Early cocking

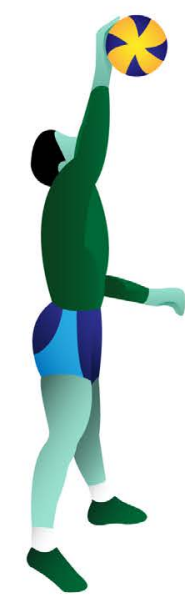

Acceleration

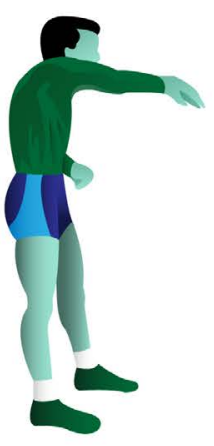

Follow-through

Figure 1: Athlete's throwing shoulder sequence adapted for volleyball.

ated to anatomical variations that reduce notch space [19]. These athletes present an atrophy of infraspinatus muscle. Its acute presentation might be painful, but, with proper rehabilitation, most athletes continue to perform satisfactorily their attacking gesture, with low pain, despite the esthetic sequel of muscular hypotrophy, without any surgery required [20].

We included rectus abdominis injuries at the pelvic injuries group, due to its importance at dynamic balance with adduction hip muscles. This relevance is observed when we look that both injuries (rectus abdominis and adductor) respond to $68 \%$ of all cases of pelvic pain during our study. This incidence of pubalgia reflects the importance of adequate core training in order to prevent this kind of injury, which lead to a new definition of those injuries by Meyers as "Core Muscle Injury", other than "sports hernia" or "athletic pubalgia" [21].

Core training is also important to prevent low back injuries, which increases its incidence with age [22]. We noticed muscular spasm and spinal disc herniation as the most frequent injuries. That occurs due to hyperextension spine movement during spikes, associated to rotational jump correction in order to increase attack effectiveness [23]. Those injuries must be considered as overuse injuries, since athletes who practice "jump serve" are more frequently affected than "floater" servers. The libero position is also at risk, due to sudden spine flexion during reception [21].

Another rare condition, that becomes only unusual at volleyball, is the Hypothenar Hammer Syndrome. This is a thrombotic injury to ulnar artery, caused by repeated trauma. It manifests with pain and paresthesia at hypothenar region, followed with Raynaud's phenomenon [24]. Treatment involves withdrawal of activities for at least two months, associated to thrombolytics. Most severe cases might require surgery. There were two athletes with this injury during our four years follow-up, none of them needed surgery, both had to be away from training for two months.

Regarding to age and position influence in injury, an interesting study was developed from FIVB Injury Surveillance System, which concluded that senior players have a greater incidence of injuries than junior players, as well as center players have also a bigger risk than other player positions. Liberos have a lower incidence, data that matches our results [1].

Our limitations to our study were the low number of participants, although the population was different since training load during all year long in national squad players is significantly higher than regular season players, which have fewer games and greater time to rest after season is over. Also, four years might still be a short time for follow-up. There is still space for further research in this area, particularly in knee's extensor mechanism tendinopathy, in shoulder balance adaptation in volleyball, especially when associated with suprascapular neuropathy, in understanding of core muscle injuries and their relation of positioning in receiving and attacking in volleyball and in a deeper approach to hypothenar syndrome in volleyball athletes.

In order to determine an adequate prevention and rehabilitation protocol, it is important to identify a few relevant risk factors $[25,26]$ :

\section{Age and gender}

2. Position

3. Number of jumps and spikes per week during training and competition

4. Kind of training court surface/kind of shoe 
5. Landing technique, with balanced coordination of both inferior limbs, and adequate knee flexion in order to impact absorption

6. Blocking technique

7. Diagnose of postural imbalances

8. Careful cinematic analysis, noticing range of motion, especially internal and external rotation, and dyskinesis of scapular movement

9. Serving and spiking technique

10. Core strengthening and stretching with trunk kinetic control and plyometric exercises.

11. Athlete's goals during upcoming season

12. Time of rest and use of painkillers

\section{Conclusion}

Volleyball exhibits some specific frequent injuries from this sport's gesture, such as knee's extensor mechanism tendinopathy, suprascapular neuropathy and hypothenar syndrome, and also present some additional mechanical adaptations to shoulder, typical of over-the-head activities. Knee, ankle and shoulder are the most affected segments during elite volleyball training, and also require specific attention at practice. Core training also have a relevant participation in prevention of pelvic and low back injuries. We suggest a careful prevention and rehabilitation protocol in volleyball in order to minimize injury incidence.

\section{References}

1. Costa L (2005) Atlas do esporte no brasil. (1 $1^{\text {st }}$ edn), Shape.

2. Reeser JC, Fleisig GS, Cools AM, et al. (2013) Biomechanical insights into the aetiology of infraspinatus síndrome. Br J Sports Med 47: 329-344.

3. Bahr R (2009) No injuries, but plenty of pain? On the methodology of recording overuse symptons in sports. Br J Sports Med 43: 966-972.

4. Bahr R, Bahr IA (1997) Incidence of acute volleyball injuries: A prospective cohort study of injury mechanism and risk factors. Scand J Med Sci Sports 7: 166-171.

5. (2015) Volleyball injury report form M-10.

6. Agel J, Palmieri-Smith RM, Dick R, et al. (2007) Descriptive epidemiology of collegiate women's volleyball injuries: National Collegiate Athletic Association Injury Surveillance System, 1988-1989 through 2003-2004. J Athl Train 42: 295-302.

7. Panni AS, Tartarone M, Maffulli N (2000) Patellar tendinopathy in athletes. Outcome of nonoperative and operative management. Am J Sports Med 28: 392-397.

8. Rees JD, Houghton J, Srikanthan A, et al. The location of pathology in patellar tendinopathy. British Journal of Sports Medicine 47.

9. Barelds I, Van de Broek AG, Huisstede BM (2018) Ankle bracing is effective for primary and secondary, prevention of acute ankle injuries in athletes: A systematic view and meta-analyses. Sports Med 48: 2775-2784.

10. Moré-Pacheco A, Meyer F, Pacheco I, et al. (2019) Ankle sprain risk factors: A 5-month follow-up study in volley and basketball players. Revista Brasileira de Medicina do Esporte 25: 220-225.

11. Lian O, Refsnes PE, Engebretsen L, et al. (2003) Performance characteristics of volleyball players with patellar tendinopathy. Am J Sports Med 31: 408-413.

12. Abdallah NA, Lee SW (2017) Patella and quadriceps tendinopathy. Musculoskeletal Sports and Spine Disorders, 273-275.

13. Everhart JS, Cole D, Sojka JH, et al. (2017) Treatment options for patellar tendinopathy: A sistematic review. Arthroscopy 33: 861872.

14. Kabacinski J, Murawa M, Dworak LB, et al. (2017) Differences in ground reaction forces during landing between volleyball spikes. Trends in Sports Sciences 2: 87-92.

15. Schleichardt A, Erber C, Wolfarth B, et al. Physiological adaptations in the dominant and non-dominant shoulder in male competitive junior volleyball players. Sports Orthopaedics and Traumatology 35: 22-30.

16. Zaremski JL, Wasser JG, Vincent HK (2017) Mechanisms and treatments for shoulder injuries in overhead throwing athletes. Curr Sports Med Rep 16: 179-188.

17. A Kugler, M Krüger-Franke, S Reininger, et al. (1996) Muscular imbalance and shoulder pain in volleyball attackers. Br J Sports Med 30: 256-259.

18. Seminati E, Minetti AE (2013) Overuse in volleyball training/ practice: A review on shoulder and spine-related injuries. Eur J Sport Sci 13: 732-743.

19. Ferreira NV, Sevivas N, Silva MV (2014) Neuropatia compressiva do nervo supraescapular. Revista Portuguesa de Ortopedia e Traumatologia 22.

20. Lafosse L, Piper K, Lanz U (2011) Arthroscopic suprascapular nerve release: Indications and technique. J Shoulder Elbow Surg 20: 9-13.

21. Poor AE, Roedl JB, Zoga AC, et al. (2018) Core muscle injury in athletes. Curr Sports Med Rep 17: 54-58.

22. Nadler SF, Malanga GA, Bartoli LA, et al. (2001) Hip muscle imbalance and low back pain in athletes: Influence of core strenghtening. Med Sci Sports Exerc 34: 9-16.

23. EALM Verhagen, AJ Van der Beek, LM Bouter, et al. (2003) A one season prospective cohort study of volleyball injuries. British Journal of Sports Medicine 38: 477-481.

24. Little JM, David A Ferguson (1972) The incidence of the hypothenar hammer syndrome. Arch Surg 105: 684-685.

25. Tone Bere, Jacek Kruczynski, Nadège Veintimilla, et al. (2015) Injury risk is low among world-class volleyball players: 4-year data from the FIVB Injury Surveillance System. British Journal of Sports Medicine 49: 1132-1137.

26. Reeser JC, Joy EA, Porucznik CA, et al. (2010) Risk factors for volleyball-related shoulder pain and dysfunction. PM R 2: 27-36. 


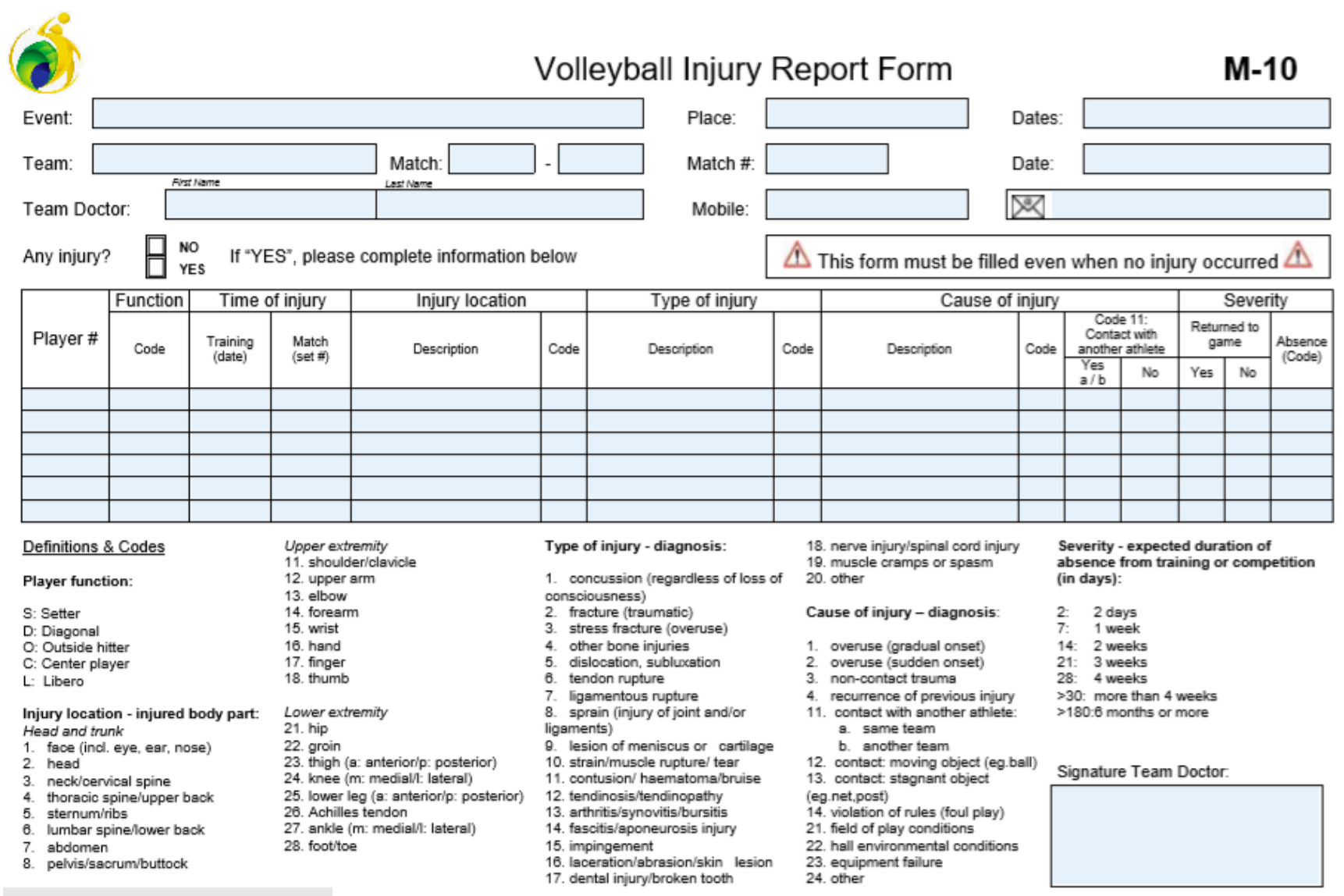

Appendix 1: FIVB M-10 Questionnaire adapted to Brazilian National Team. 